\title{
Cosmovivencia Andina. Vivir y convivir en armonía integral - Suma Qamaña ${ }^{1}$
}

\author{
Simón Yampara Huarachi \\ Movimiento Katarista de Katari para la \\ Complementariedad
}

\begin{abstract}
This work discusses key concepts for the understanding of an Aymaran epistemology as part of a decolonization process that equally affects the culture, politics, economy and the history of Bolivia. The frame in which the discussion of these matters takes place (an academic event in the United States) opens up a debate on the epistemological nature of the relations South-North.

Keywords

Ayni, Convivialidad, Cosmoversity, Pachakuti, Qhathu 16 de Julio, Qullana, Suma Qamaña, Tetralectic Logic, Tiwanaku
\end{abstract}

\section{Resumen}

En este trabajo se discuten conceptos claves para la comprensión de la epistemología aymara como parte de un proceso de descolonización que afecta en igual medida a la cultura, la política, la economía y la historia de

1 Este trabajo es una versión escrita de la ponencia presentada en la Conferencia Inaugural del Bolivian Studies Journal/Revista de Estudios Bolivianos que tuvo lugar en Pittsburgh, el 25 de febrero de 2011. 
Bolivia. El marco en que se realiza la discusión de estas materias (un evento académico en Estados Unidos) obliga además a debatir la naturaleza epistemológica de las relaciones Sur-Norte.

Palabras claves

Ayni, Convivialidad, Cosmoversidad, Lógica Tetraléctica, Pachakuti, Qhathu 16 de Julio, Qullana, Suma Qamaña, Tiwanaku

Primero que nada quisiera agradecer a Chris Krueger $^{2}$ por haberme puesto en contacto con Pittsburgh, y a las editoras de la Revista de Estudios Bolivianos por haberme invitado a tener voz directa en esta conversación. Esta es la primera vez que estoy en este país, Estados Unidos. Por primera vez estoy tratando con otros aynis, con otras energías. Antes de iniciar mi presentación quisiera decir que yo no sé si voy a hacer buena o mala literatura para esta academia. En esto tengo una interrogante y una reflexión interna también, porque no sé de qué literatura vamos a hablar. ¿Literatura boliviana? ¿Latinoamericana? o ¿literatura en general? A propósito, yo propongo literatura Qullasuyana, Tahuantinsullana y abyayalana, ${ }^{3}$ y me pregunto cuál de estas posibilidades de la literatura será más adecuada... Estamos acostumbrados a hablar de "lo boliviano", de "lo latinoamericano", o cosas así, y ahora veo que también se está hablando de estas cosas desde la perspectiva de un diálogo Norte-Sur. Yo puedo hablar desde la relación colonos-colonizados, pero me parece más difícil hablar desde la relación Norte-Sur. Con esa relación creo que todavía hay que tener reparos porque plantea problemas de tipo identitario, de tipo de saber cómo conocer realmente el Sur, porque el Sur no creo que antes de 1825 era Bolivia, ni América era América. Recién lo es. Entonces ¿qué era el Sur antes de ser colonizado? Creo que ahí tenemos que buscar algunos elementos para que realmente se pueda tener un diálogo fructífero Norte-Sur, una conversación fructífera que pueda ser amena también. Pero aparte de esto hay un elemento más que nos falta para llevar a cabo una conversación plena. Ayer, cuando conversaba con algunos estudian-

${ }^{2}$ Coordinadora de la Sección Bolivia en LASA y de la Red Bolivia Mundo.

3 Qulla, Qullana [Collana], según Bertonio, es "excelente", "primero" (nayra), de donde sería el primer espacio sano, espacio con primeras medicinas. Suyu es territorio, de donde Qullana-suyu es un primer espacio territorial sano, con primeras medicinas, territorio con salud ecológica saneada naturalmente [suma nayra q'uma marka uraqi], parte del Tawantinsuyu. Abya-Yala es "tierra fértil "y proviene de la cultura Kuna de Panamá. 
tes sobre estos mismos temas, veía que en la sala todos tenían sus agüitas, sus refrescos, pero a mí me faltaba la hoja de coca. Ese es un problema, porque resulta que para los aymaras, para los quechuas, sin la hoja de coca no hay una conversación seria ni responsable. Menos puede constituirse una comunidad de conversación. Lastimosamente aquí, por una serie de factores, la coca no puede circular, no podemos tener coca en este momento, pero hubiera sido interesante tenerla para ritualizar la conversación, porque en aymara todo trabajo meditado es ritual, se inicia y termina con actos rituales. Bueno, con esas consideraciones, vamos a tratar de empezar esta conversación sobre la que tengo mis dudas... No sé para qué, para quién la hacemos... ¿Para la academia? ¿Qué hace la academia con esto? Este es un cuestionamiento que yo mismo me hago también.

Uno de los temas mayores que me gustaría conversar con Uds. es este problema del cambio/transformación en el que está Bolivia y a su vez el Pachakuti que se ha iniciado. Me parece que "cambio" y "transformación" son conceptos que hay que leer juntos, leer como el "cambio de transformación", porque una cosa es el "cambio" dentro del sistema mismo que conocemos y que nos da alternativas, como por ejemplo la dicotomía entre las políticas de derecha e izquierda. La derecha quiere sustituir a la izquierda y la izquierda a su vez a la derecha. Creo que en eso consiste la idea convencional del "cambio" y de hecho ése ha sido el único cambio que siempre se ha practicado en Bolivia y que sigue el modelito de estatizar o neoliberalizar. Eso parece entenderse como "cambio", como "cambiar". De repente, es cambio de guardia nomás, cambio de regímenes políticos y nada más. Ahí ya hemos hecho cambio. Pero me parece que la cosa va más allá, porque de por medio hay espacios, espíritus... Está el espíritu colonial, está el espíritu del sistema del capital, ¿cómo lograr cambiar realmente eso? Yo creo que ahí está el problema. Ahí yo veo un problema mucho más profundo. Ahí es donde veo la posibilidad del Pachakuti.

Y hablando de Pachakuti, uno se pregunta: pacha, ¿qué es? Pacha es doble fuerza, energía. Kuti, el retorno. Permanentemente, por ciclicidad de visiones, va-viene la pacha. Se trata de un permanente cambio, renovación de energías, de fuerzas. Los mundos aymara, quechua, qullana, están buscando eso, mientras otros estarían buscando lo otro: un cambio de guardia. Entonces tenemos que saber qué estamos buscando y preguntarnos qué está buscando el actual gobierno. Ésa es la pregunta. O sea por dónde va el gobierno. En mi criterio, va nomás en busca del cambio de guardia. No está yendo al pachakuti. No le interesa. Le interesa un "cambio" de sistemas políticos y por eso va acuñando esa cuestión de la izquierda aunque remozada de indigenismo. O sea es un 
gobierno prisionero y colonizado por las ideologías de la izquierda. No es un gobierno indígena como generalmente piensa la gente. Me parece que es importante destacar esto. El hecho de que cada 6 de Agosto se haga desfilar a 36 nacionalidades es utilizar los símbolos, decir "bueno, todo eso representamos" y "bajo el mandado de eso estamos", pero en el fondo la cosa no es así. En el fondo estamos nomás colonizados, catequizados. No en vano Evo Morales se ha formado en la zona cocalera del Chapare, que es zona de colonización. Ése es su espacio de movimiento, ahí ha agarrado el campesinismo y el sindicalismo, pero con las ideas del clasismo de los centros mineros. Entonces, en ese sentido, yo creo que una primera cosa que hay que aclarar es esta cuestión del "cambio". Entender que el "cambio" y el pachakuti son dos horizontes distintos.

Rápidamente, porque el tiempo también no nos alcanza, voy a hablar de cómo en el giro político boliviano se va de un populismo a otro populismo. Desde mi lectura, hay un doble populismo en Bolivia. El 52 lo conocemos como el populismo de la derecha, con un mestizo de presidente, que es Víctor Paz Estensoro - cuyas medidas ya las conocemos y que han durado del 52 al 64. Ahora, después de años, vuelve el populismo, pero esta vez desde la izquierda, más o menos desde el 2005 al 2011. En periodos, Paz Estensoro duró más tiempo que Evo Morales. Evo Morales en el 2011 está en un momento ya de la pérdida, de curva descendente, es decir hay una tendencia a la descendencia y a la emergencia de otras alternativas. Además, creo que hay un paralelismo en las medidas que toman estos populismos. Por ejemplo: tenemos nacionalización de minas y nacionalización de hidrocarburos. Voto universal y Asamblea Constituyente y la nueva Constitución Política del Estado. Tenemos Reforma Agraria y ley INRA y TCOs. (Tierras Comunitarias de Origen), Reforma educativa y Ley Avelino Siñani y Elizardo Pérez. Son casi similares o parecidas estas reformas. ¿Dónde está la diferencia? Y además, hay que hacer notar que en el 52 se hablaba de "cambio". Querían cambiar, cuando sólo había habido cambio y reciclaje de ciertas roscas. Yo no comparto la idea de élites. Hay roscas de por medio, y ahora en Bolivia está pasando lo mismo. Hay otro tipo de roscas que se están generando con Evo Morales y que están produciendo un "cambio" de guardia. En lo único que realmente se puede ver un "cambio" de verdad es en esta autoestima indígena que de alguna manera ha aparecido. Pero el resto no ha cambiado. El resto sigue, las estructuras coloniales un poco pro-capitalistas, eso sigue, y lo hemos visto con el problema del gasolinazo (que lo han llamado 
gasolinerazo). ${ }^{4}$ Entonces se ha visto que no había cambiado para nada la estructura económica del país. O sea siguen las medidas neo-liberales que existían antes. El decreto 21060 continúa nomás en su curso. Lo mismo la estructura estatal, diseñada bajo principios mono-nacionalistas. Todo eso casi intactamente sigue, pero en el discurso nos están vendiendo la idea de lo plural, del interculturalismo, y la idea de que la cosa está cambiando. O sea nos venden el discurso. Una cosa es discursar y otra cosa es realmente hacer las cosas. No vemos ahí sinceramente que haya cambios, salvo haber elevado la cuestión de la autoestima indígena.

Yo creo que hemos transitado de un populismo de derecha a un populismo de izquierda y de un poli-clasismo a un pluri-nacionalismo. Pero sólo en discurso. Ésa es la situación. La colonización, la colonialidad y el sistema de capitalismo siguen vigentes, como también la falta de gestión estatal y de estrategias de producción agropecuaria. Por otro lado, nos movemos en una especie de pandemia, una especie de tres enfermedades que adolecemos como humanidad y que tienen que ver con la crisis del sistema de valores. Una es la cuestión del alcohol. Otra es la religión y las sectas religiosas, y la otra es la cuestión de las drogas, en este caso puede ser marihuana y cocaína. Conceptúo que Occidente, de una u otra manera, lidera esta crisis de sistema de valores. Pero con esta autoestima indígena, podríamos decir que también hay una especie de re-emergencia de otro tipo de sistema de valores. Esta crisis de sistema de valores y la emergencia de otro sistema de valores es algo que hay que conversar, que hay que discutir, pero hasta ahora el tema está invisibilizado. Alguien me va a decir que bueno ... esa dicotomía... Yo no quiero la dicotomía, es más, protesto contra eso, pero veo que estamos frente a dos sistemas de valores civilizatorios (más que frente a procesos interculturales). De repente, las palabras que uso no son propias para esta discusión, puede ser, me pueden cuestionar, me pueden decir "no tienes razón". Pero para entendernos creo que es importante decir lo que estoy pensando.

$Y$ digo que en este sistema de valores civilizatorios una cosa es lo ancestral milenario que viene desde Tiwanaku, probablemente más antes. Alguien dijo "yo me siento Inca". Pues me pareció interesante pensar así... yo me siento por lo menos piedra de Tiwanaku. Entonces

${ }^{4}$ La VIII Marcha Indígena del Territorio Indígena Parque Nacional Isiboro Sécure (TIPNIS) es posterior a la escritura de este trabajo. La posición de Yampara frente al TIPNIS puede verse en "EI Movimiento Katarista de Katari para la Complementariedad MKC frente al TIPNI" [www.políticasparabolivia.com/?p=549]. Nota de las editoras. 
esa es la cosa: Tiwanaku a un lado. Al otro lado la invasión colonial y lo que vino con ella, que ha creado el mundo que vivimos ahora. De una u otra manera el mundo se mueve en ese espacio creado por la invasión colonial. No veo un ayni (reciprocidad) entre los dos sistemas. Por eso al comenzar esta conversación me preguntaba si vamos a hablar de Latinoamérica, de Bolivia, de Qullasuyu, de Abya-Yala... Aquí tengo problemas yo también. ¿Desde dónde puedo yo entender la semilla, la identidad? Es decir es un cuestionamiento que yo me hago también. En este sentido ¿cómo pensar sólo bajo la vertiente de la invasión? Por eso vienen los centenarios, los bicentenarios, los quinto centenarios, o sea la historia se hace centenaria en Bolivia. No se hace milenaria. Lo milenario hay que taparlo, enterrarlo bajo tierra. En todos los horizontes estamos celebrando los centenarios. A mí me parece que los centenarios son una manera de encubrir lo milenario, una manera de encubrir y decir "bueno miren, aquí están los valores, lo centenario aquí está". Entonces yo pienso que ahí hay problemas, problemas de tipo cognitivo, problemas incluso de una especie de doble analfabetismo. Unos somos analfabetos en centenarismos, otros somos analfabetos en milenarismos. Probablemente la academia nos ha alfabetizado en uno de ellos, pero en el otro nos deja con ceguera cognitiva. ¿Cómo resolver eso? Pues sigue siendo un problema. ¿Académicamente, será posible resolver eso con la curricula, con la manera como está concebida la educación? Yo tengo incógnitas ahí. No hay una Universidad perfecta. No es una Universidad, es una Cosmoversidad lo que requerimos para realmente estudiar, porque eso de universidad quiere decir una visión, una versión de la vida, y la cosmoversidad puede ser algo distinto a la universidad. Y ahí entro un poco en el problema de la cosmovisión y la cosmoconvivencia andina, que para mí no es lo mismo. Una cosa es la cosmovisión, la visión de uno al mundo; y otra cosa es la cosmoconvivencia de existir. Voy a tratar de explicar esto.

La cultura Andina ha sobrevivido estos embates de cinco siglos. ¿Cómo ha podido sobrevivir? La única respuesta es que ha sabido sobrevivir porque sabe convivir con los diversos o sea, no sólo con la diversidad, sino con los diversos mundos. Y aquí hay algo importante, porque no se preocupa sólo del mundo de la gente, egoístamente, como occidente parece preocuparse sólo del mundo de la gente y hasta nos han hecho creer que el único ser racional e inteligente es el ser humano, y por ahí viene todo el paquete del "desarrollo humano". Entonces, ¿qué pasa con los otros mundos? Resulta que los aymaras vivimos $y$ convivimos con el mundo animal, con el mundo vegetal, con el mundo de las deidades y con el mundo de la tierra. Si esos mundos están bien, el 
mundo de la gente también estará bien. Pero no a la inversa, que primero el mundo de la gente esté bien sin importar cómo estén los otros. Creo que la lógica del sistema occidental es sacar el mayor provecho para el mundo de la gente y no preocuparse del bienestar de los otros mundos. Pensar en los otros mundos tiene que ver con la cultura de la convivencia, o sea la convivialidad, la cosmo-convivencia, que es diferente al concepto occidental de "cosmovisión".

Ha sido esa capacidad de convivialidad lo que, estratégicamente, ha hecho que en los Andes pueda sobrevivir esto que llamamos el mundo indígena. Claro que para sobrevivir, muchas veces se ha tenido que camuflar. Cuando trabajé en Carangas, por ejemplo, vi a unos mallkus (autoridades locales) con sus ponchos, sus lazos y cosas así, que se habían puesto medallones icon la imagen de Jesucristo! La primera vez que los vi yo decía "cómo es posible que estos mallkus sean originarios cuando son hijos de Cristo, con su medallón". Ahí está la señal que todos miramos. O sea que cuando vemos con ojos externos, eso miramos. Pero cuando uno asiste a sus ceremonias rituales, a sus wajt'as (convidación), wilanchas (libaciones), phuqanchas (cumplimiento de obligaciones), ve que desde las cinco o seis de la mañana los mallkus y las t'allas (señores y señoras principales de la comunidad) salen al cerro y llevan a las dos deidades de la marka, una deidad con valores de la masculinidad y una deidad con valores de la feminidad. Las dos deidades pareadas. Entonces salen en orden de jerarquías, comenzando con los mallcus. Van todos con sus familias a hacer su ceremonia ritual, allá abajo, en el pueblo donde está el santo Santiago. Pero ni por curiosidad han visitado ni han pedido permiso al santo. Se fueron nomás allá y han hecho todo el día sus emulaciones a la Pachamama y los Achachilas, compartiendo bebida y comida con las deidades, pero ninguno estaba borracho. Recién entendí que el medallón era simplemente una especie de camuflaje para decirle a tanta inquisición "mira, soy hijo de Cristo, por lo tanto créanme que soy cristiano y hasta pueden hacer estadísticas de que ya soy cristiano pues, hijo de Cristo". Pero en el fondo no eran cristianos, sino que practicaban sus ritos en los Andes y estaban emulando sus energías con las deidades naturales. Las deidades naturales eran más importantes que el santo, en este caso Santiago, que está en la iglesia a la que alguna vez van, pues les sirve para disimular.

Pues con ese camuflaje logré entender que hasta en la indumentaria hay una situación de camuflaje. Ahora mismo yo estoy vestido pues como los mestizos también, no por eso soy mestizo ni pienso como mestizo. Lo que quiero mostrar entonces es cómo el ayni, la correspondencia recíproca, la emulación de las diversas energías, se convierte en ceremonia ritual, eso que dicen el "paganismo", eso que 
dicen la "brujería", eso que dicen el "chamanismo". No sé qué otros nombres más le ponen a esa actividad que es la emulación, la articulación de las energías de los diversos mundos. Finalmente, uno se pregunta qué es la vida, porque estamos preocupados por la vida, y la vida no había sido más que manejo del doble tipo de energía: la energía material con la energía espiritual, y cómo usas y disfrutas eso: de forma privada y de forma comunitaria. Eso es lo que se hace en los Andes. En la organización del ayllu las familias usan la energía interactivamente, reconcilian lo material con lo espiritual, tratan de equiparlos como si fuera un matrimonio, usan la energía de forma privada pero también de forma comunitaria (que no es lo mismo que colectivista).

En la lección marxista nos habían dicho que la lógica dialéctica era la más apropiada para el conocimiento, pero en el modelo andino nos encontramos con una lógica de cuatro elementos, entonces somos la doble dialéctica, la tetraléctica. Cómo procesar la tetraléctica es otro desafío que tenemos que enfrentar. Para entender eso me encuentro con dos palabras: tawa (que en quechua significa cuatro) y Tiwana (cuatro en aymara), de donde viene Tiwanaku (semillero de organización de cuatro ángulos de la tierra) y Tawantinsuyo (lugar donde el armazón de la vida está entre cuatro espacios de la tierra, entre cuatro ángulos). Creo que por ahí se puede entender esto de la cosmoconvivencia, que quiere decir procesar, usar y disfrutar interactivamente la energía material y espiritual, y al mismo tiempo ordenar la vida de manera convivencial con los diversos mundos y espacios, emular esas energías que cada uno tiene en un proceso de ayni. Aquí entro al problema de tejer la cosa, porque se trata de hacer un tejido, un textil andino.

Antes de entrar a ese textil que es el mundo andino, quisiera hablar también de cómo cultivamos los saberes y conocimientos, cuáles son nuestras fuentes primarias para cultivarlos o, en otras palabras, para hacer ciencia. En general, me parece que a lo más que llegamos es a las fuentes secundarias, a las crónicas coloniales. Hasta ahí parece que llegamos. Más allá, a las tierras de Tiwanaku, ya no. Por eso les decía que yo quisiera ser piedra de Tiwanacu. En este sentido quisiera estar en el Sur, hablar desde el Sur. Entonces Tiwanaku, la iconografía de Tiwanaku, no la estudiamos, no la miramos como fuente primaria de conocimiento, sino más bien como conjunto de reliquias, como ruinas que arruinan la conciencia si miramos. Por eso dicen que a estas ruinas de Tiwanaku o de Machupichu hay que ir como turistas. Y como turistas las miramos como si fueran una curiosidad. Al guía turístico que nos cuenta el cuento de los incas le decimos ¡Qué lindo! ¡Cómo habrán sido los incas! Pero no hemos mirado las piedras de Tiwanaku o Machupichu, 
no hemos pensado porqué están ahí, porqué son como son, porqué tienen las formas que tienen. No. Sólo las hemos mirado como curiosidad, y con eso nos hemos conformamos. Pero cuando el estudio de Tiwanaku forma parte de la curricula educativa, entonces la iconografía se convierte en una fuente de conocimiento.

Otra fuente de conocimiento son las toponimias, porque los nombres de los lugares tienen sentido y significación. Un nombre no está ahí porque sí. Por ejemplo "Copacabana". Mucho se habla de "Copacabana" como la virgen de Copacabana y todos piensan en la virgen, en la fe católica a la virgen. Pero ese lugar que llamamos Copacabana era un observatorio astronómico ( $\left.k^{\prime} o p a\right)$ que tenía que ver con la chakäna, que es una comunidad de estrellas que forma la figura de la cruz del sur. En los Andes se conoce como la cruz cuadrada de Tiwanaku, y refleja el comportamiento climático y su significación en la producción ecológica. En el mes de mayo se veían las estrellas, pero no se las miraba arriba, sino abajo, en el agua, en el lago. En la espuma del lago. El movimiento de esa espuma indicaba cómo iba a ser el comportamiento ecológico del año. Eso era "Copacabana". La virgen de Copacabana es algo totalmente distinto e impuesto sobre un ritual aymara.

Pasa lo mismo con "Cochabamba", con "La Paz". Todos estos nombres están impuestos, como si sobre una fachada hubiéramos impuesto otra fachada. Y sobre eso queremos hacer literatura, sobre fachadas que borran la estructura de pensamiento de una de las fachadas. Entonces esto ya es un problema. Pero además de lo que ya he dicho, la toponimia conlleva también otra fuente de información, que es la memoria comunitaria, que se transmite de generación a generación. La gente del Taller de Historia Andina ha trabajado esto, pero en principio la idea era nuestra, nosotros hablábamos de la memoria comunitaria andina. Pero en todo caso lo importante es que la "memoria" es otra fuente de conocimiento y que hay muchas formas de conservarla. Una de ellas es la que encontramos en los textiles. Aquí tenemos una chuspa que parece ser un textil jalca, pero está todavía ordenada a lo occidental (figura 1). 


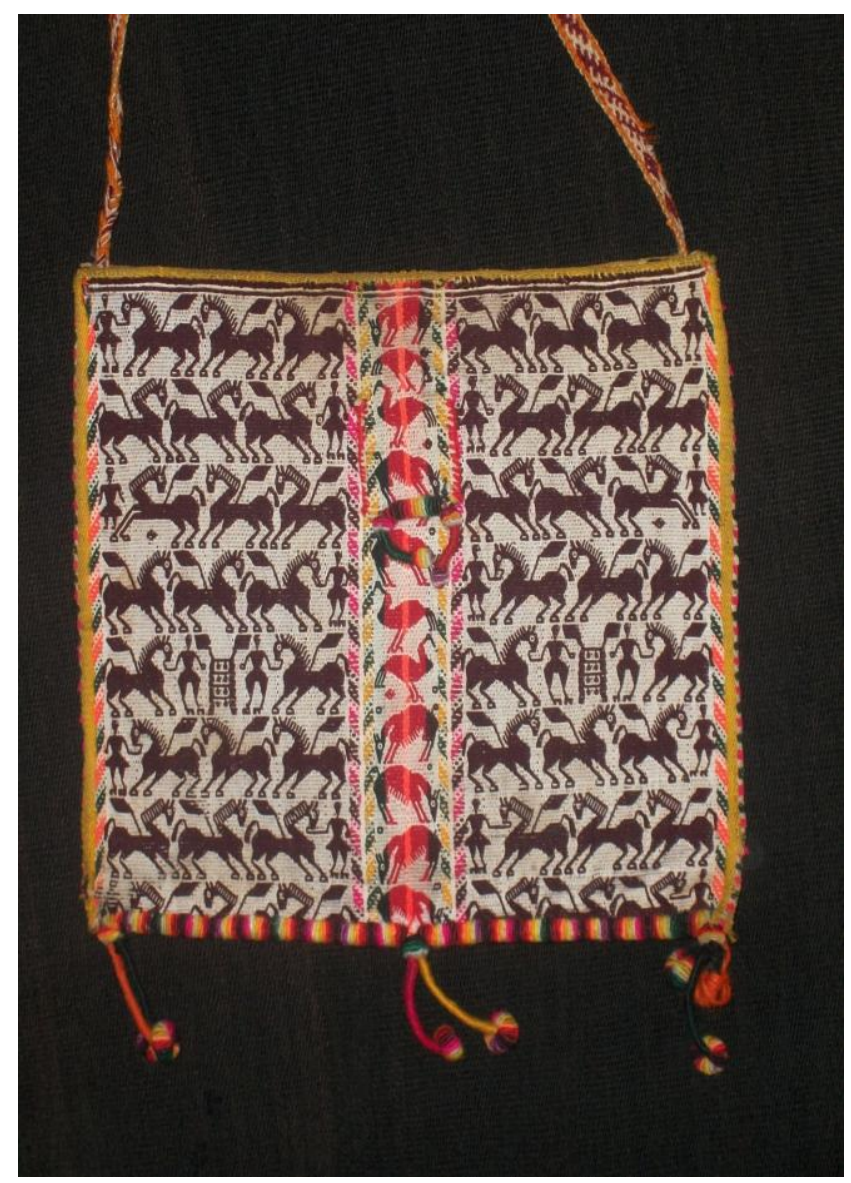

Figura 1: Chuspa Candelaria ${ }^{5}$

Colección Privada

Fuente: Agatha Monasterios-Ramírez. Archivo fotográfico

5 "Candelaria" es el nombre de una hacienda colonial situada a 26 kilómetros de Tarabuco, Chuquisaca. La hacienda y sus alrededores conforman un importante centro de producción textil. 
Hay otros textiles no ordenados de esta manera, que se salen de este tipo de orden. Éste, por ejemplo (figura 2).

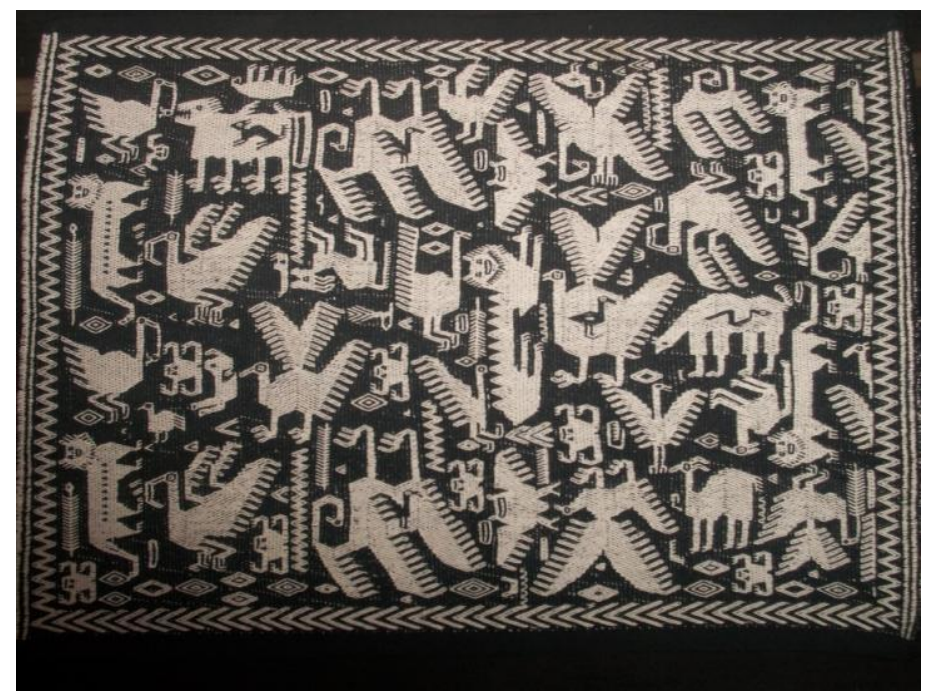

Figura 2: Aqsu jalc'a

Colección Privada

Fuente: Agatha Monasterios-Ramírez. Archivo fotográfico

¿Cómo leemos esto? ¿Cómo lo podemos entender? Generalmente estos textiles están tejidos por gente que no sabe leer español, aymara, nada. Para entender lo que han tejido nesitamos otros instrumentos. El pensamiento andino se parece a este diseño, es de tipo axiomático. Una sola palabra puede tener siete $u$ ocho acepciones a la vez, por eso es imposible afirmarse en la dialéctica del "si" y del "no" para entender la lógica del pensamiento andino. Yo creo que en todas estas cosas de las que he hablado hay elementos para pensar un pensamiento que no es occidental. Tenemos las piedras, tenemos la memoria, tenemos las toponimias, los textiles, tenemos todo esto pues. $Y$ yo no sé qué otras cosas más haya. Yo me pregunto si a la academia le interesa cultivar estas fuentes para realmente hacer conocimiento, hacer ciencia.... Éste es el cuestionamiento que yo me hago y que quiero compartir con Ustedes, que son la academia. 
Entonces cuando hablamos de la cosmoconvivencia Andina estamos hablando de estos diversos mundos que de una u otra manera también están graficados en los textiles: el mundo animal, el mundo vegetal, el mundo de las deidades, el de la naturaleza, la tierra, y el de la gente que hace estos tejidos. Por eso tenemos que tener cuidado cuando pensamos en las fuentes. A veces concluimos que con la literatura existente y con la información de las crónicas coloniales ya tenemos todo... Pero rastreemos un poquito la historia... Guamán Poma de Ayala, por ejemplo, nos ha dejado un mapa indicativo que dice que es un mapa pontifical (figura 3).

Cuando miro este mapa veo que evidentemente obedece a dos sistemas de valores civilizatorios. Aquí dibuja Cusco y aquí dibuja Castilla, o sea como dos horizontes. Castilla por un lado y Cusco por otro lado. $O$ sea el horizonte de Cusco es una cosa y el horizonte de Castilla es otra cosa. Cuando digo que estamos frente a dos sistemas de valores civilizatorios me estoy refiriendo a esto; a lo que en los últimos tiempos ha pasado en Bolivia, cuando en el 2003, cuando se hace la revuelta indígena, sale Felipe Quispe ${ }^{6}$ y dice "hay dos Bolivias". ¿Dos Bolivias? ¿O más bien hay un Collana suyo y Bolivia? Ya años antes había dicho Fausto Reinaga ${ }^{7}$ eso de las dos Bolivias. Hasta ahora es un problema irresuelto esto de Bolivia o de Collasuyo. Guamán Poma ha escrito sobre este problema en el siglo XVII y lo ha dibujado. Pero hasta hoy día hay una incomprensión histórica respecto a esto. No entendemos adecuadamente la situación, y esto es preocupante. Ni académica ni políticamente estamos entendiendo esto. Tampoco sabemos cómo vamos a estudiar esta cuestión de la interconexión entre civilizaciones y procesos inter-civilizatorios, procesos de inter-aprendizaje y armonización de energías.

El paradigma de vida que se ha simplificado como Vivir Bien (Suma Qamaña) tiene que ver con todo esto. Pero es importante entender que

6 Felipe Quispe Huanca "El Mallku" (cóndor en lengua aymara), es un histórico dirigente indígena y líder de la corriente más radical del momiviento indio en Bolivia. En 1999 fue Secretario General de la Confederación Sindical Única de Trabajadores Campesinos de Bolivia (CSUTCB) y en el año 2000 fundó el Movimiento Indígena Pachakuti (MIP). Quispe trabaja por el restablecimiento de una nación indígena cuyo nombre debería ser "Collasuyo".

7 La producción intelectual de Fausto Reinaga (1906-1994) se concentró en la discusión política e ideológica. Reinaga es considerado como un referente ideológico para los militantes kataristas-indianistas. 


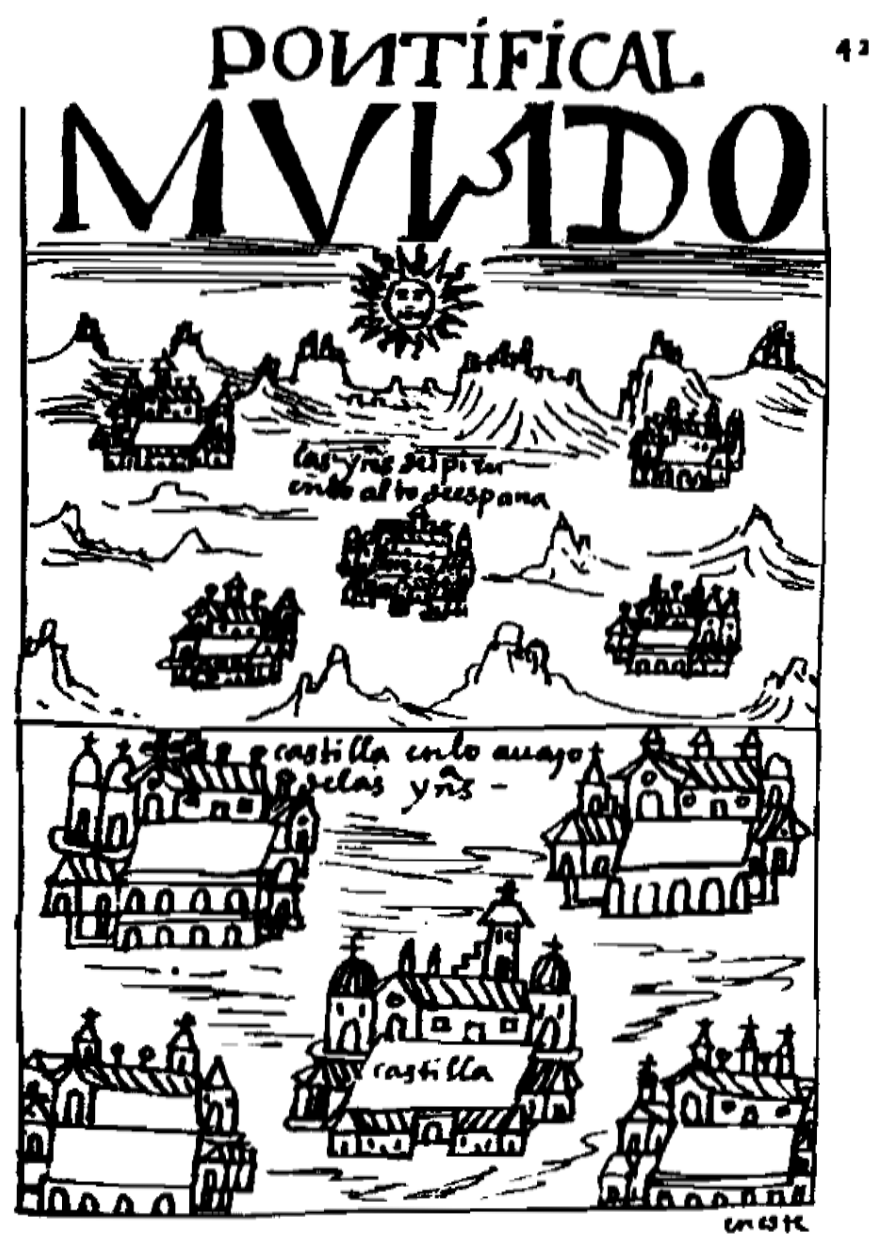

Figura 3:

Fuente: El Primer Nueva Corónica y Buen Gobierno llustración $\mathrm{N}^{\circ} 42$

el Suma qamaña, que es vivir bien en armonía integral, vivir y convivir, no sólo se refiere a vivir, sino también a vivir y convivir con la muerte. Entre la muerte y la vida está Suma Qamaña como acción intermedia. Hay que tener cuidado cuando ese "vivir bien" se desplaza al "vivir mejor", porque "vivir mejor" implica la comparación, implica que mientras unos viven 
"mejor" otros van a vivir "peor," y por tanto se pierde esta cuestión de armonizar los diversos mundos, las energías de los diversos mundos. Esta es una de nuestras reflexiones al gobierno de Evo Morales, pero al mismo tiempo una reflexión al interior del mundo aymara y quechua, al interior de eso que algunos llaman los pueblos "indígenas". La palabra "indígena" también es una palabra colonizada. En Bolivia ya hay tres palabras peligrosamente constitucionalizadas: una que dice lo "indígena", otra que dice lo "originario" y otra que dice el "campesino". Cuando se habla de campesinado sindicalizado, por ejemplo, en el fondo se está hablando de campesinado colonizado y prisionero de la izquierda estalinista. Y sin embargo, en la imagen externa, las palabras se muestran como discurso de un gobierno indígena. Podrá ser indígena o "para indígenas", pero no es propiamente ni aymara ni qullana ni nada de eso. Es otra cosa.

Entonces estamos frente a un proceso que acuña palabras y les pone apellido. A la cuestión del "socialismo," por ejemplo, le están poniendo apellido comunitario: socialismo comunitario. También a la bandera, que dicen la bandera boliviana, le aumentan la whipala. Se quiere forzar dos paradigmas en uno, porque el socialismo corresponde al paradigma del desarrollo, y lo comunitario -tomado en sentido andino- correspondería al paradigma de vida del Suma Qamaña. En la propuesta de "socialismo comunitario" desaparece el paradigma milenario andino y sigue funcionando el paradigma centenario del desarrollo con el saludo comunitario a la bandera. En todo esto hay un bambaleo y ya no se sabe si el modelo económico que se busca es un capitalismo andino o un socialismo comunitario. Lo que sí está claro es que las medidas, las acciones, las políticas que se están haciendo siguen obedeciendo al modelo del desarrollo y no se diferencian tanto de lo que hacía el Estado colonial. Este modelo del desarrollo no entiende la perspectiva qullana cosmo-visionaria que los aymaras tenemos del qhathu (mercado), por eso el horizonte del desarrollo económico del país está completamente condicionado al mercado del gas y las importaciones de diesel y otros carburantes. Es decir el desarrollo está hipotecado.

La política fundamental del gobierno del MAS (Movimiento al Socialismo) ha sido la profundización del rentismo como expresión de continuidad colonial y neoliberal, con máscara de redistribución de lo ínfimo hacia los más pobres, pero conservando el grueso de los ingresos en el $20 \%$ de la población más rica (último informe de PNUD). ¿Y qué pasa con el resto? ¿Dónde está el $80 \%$ de la población? Ese resto está practicando economía informal, y ahí viene el problema del qhathu 16 de 
Julio (mercado 16 de Julio). ${ }^{8}$ El qhathu 16 de Julio es un sistema de autogeneración de empleo, de ocupación, y de riqueza. La dinámica socioeconómica del qhatu se parece al textil andino... tiene ese orden o desorden (figura 4).

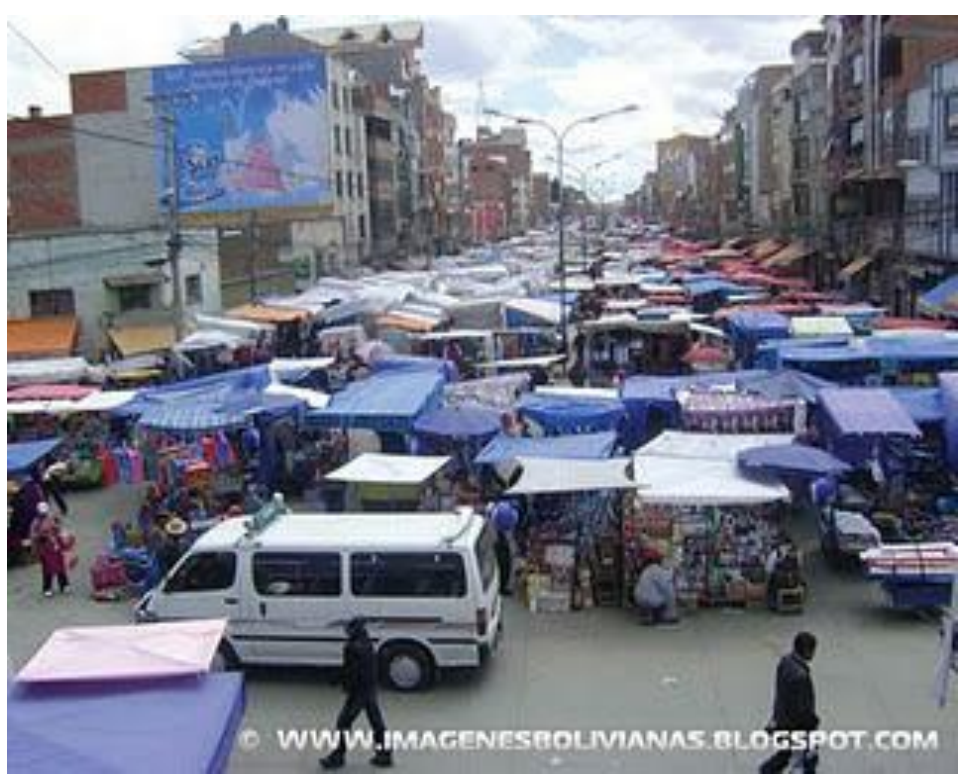

Figura 4:

Qhathu 16 de Julio

Fuente: www.imagenesbolivianas.blogspot.com

En otras palabras, el mercado aymara es un ciclo de producción que incluye consumos materiales y espirituales. La tríada producción / feriaqhathu / celebración moviliza a las asociaciones en la elaboración de valores culturales todo el año hasta que llega la fiesta anual, que es una entrada como la del Gran Poder, en la que tanto la producción como la

8 Para un estudio detallado del funcionamiento económico de este mercado informal se puede ver el libro: "Matrices de civilización. Sobre la Teoría Económica de los Pueblos Andinos" por Simón Yampra y Dominique Temple. La Paz, Altu Pata/El Alto, ediciones Qamañ Pacha/Fundación Qullana Suma Qamaña « Fdqsuqa », 2008. 
transacción son celebradas. En todo este circuito económico se hace economía, se hace plata, se genera riqueza. Pero hay que entender que la noción de "riqueza" para los Aymaras tiene que ver con la adquisición de un otro sí (el otro yo). Entonces iojo! cuando desarticulamos ese circuito y lo folclorizamos, por ejemplo sólo vemos la entrada, o el qhathu de los indios, o la producción, los talleres, los microempresarios, estamos distorsionando todo el proceso. Por ese circuito se mueve la economía de los qullanas y de los aymaras, que además de hacer circular productos nativos del lugar están conectados al circuito geopolítico-económico del pacífico sur: China, Japón, Corea y Brasil en tránsito por Chile. En el qhathu todo circula, hasta productos que para nosotros son basura. Las basuras también sirven allá. O sea nada es desechable. Esta lógica de que "todo vale" en los Andes, de que de todo se extrae conocimiento y beneficio, se parece a una pelota de trapo que está hecha con restos de muchas cosas. En los Andes la gente sabe convivir con esa lógica de la pelota de trapo. Aquí sirve conocer la palabra qamiri, que significa "colcha", "sleeping andino" hecho de los retazos de la ropa usada. La gente que sabe vivir y convivir con los diversos mundos duerme sobre esa acumulación. La gente civilizada como nosotros, que dormimos en el sobre de sábanas, no conoce esa lógica del qamiri. Qamiri entonces es el jaqui (persona) que sabe vivir y convivir en y con todos los diversos mundos de la naturaleza. No es el ser rico. Menos todavía ser "burgués". Por eso se desubican los que extienden la categoría y título de "burguesía" a los indígenas y cholas del qhathu 16 de Julio.

Bueno, y ya para terminar, quisiera decir que tengamos cuidado con la palabra "indigenismo" que usa la gente no indígena. El indigenismo no es preocupación ni de los aymaras ni de los qullanas. La gente no indígena hace indigenismo. Otra cosa es el "indianismo", otra el "katarismo" y otra muy distinta la izquierda stalinista. No hay que confundir estos términos. Algunos se sienten muy cómodos y dicen "bueno, soy de izquierda progresista" y no se dan cuenta que ahí está el rollo, el desarrollo, el progreso. De una u otra manera la izquierda progresista está nomás dentro del paradigma de vida del rollo del desarrollo, del progreso. Los seres qullanas estamos pensando de otra manera. Queremos convivir con los diversos mundos, incluido el mundo de la gente que es diferente a nosotros, incluido el sistema del capital. Pero también queremos que se respete nuestro propio modelo de organización, de economía, de manera de ser. En este sentido queremos forjar respeto mutuo entre diversos. Conocimiento ancestral milenario + conocimiento occidental centenario $=$ conocimiento profundo $\mathrm{y}$ renovado. ¿Por qué no podemos hacer esa ecuación? 


\section{Glosario}

Abya-Yala: En lengua kuna significa "tierra en plena madurez" y es utilizada por el pueblo Kuna de Panamá para referirse al continente americano desde antes de la llegada de Colón.

Achachilas: Son espíritus de protección de los aymaras cuyo hogar ancestral son los Andes. Los achachillas son antepasados que mantienen un ojo vigilante sobre sus descendientes, ofreciendo la asistencia necesaria cuando es solicitada. Aparecen en los sueños y ofrecen advertencias para que situaciones desafortunadas o peligrosas se puedan evitar. También tienen poder sobre las precipitaciones como la lluvia, granizo y heladas.

Ayllu: $\quad$ Forma andina de comunidad que emula las cuatro fuerzas que constituyen la vida (materia, energía, tiempo y espacio). De acuerdo a Raúl Prada, la estructura social del Ayllu responde a la necesidad de complementar suelos, de hacer circular los productos, de hacer rotar los trabajos. Los mandos rotativos del poder comunitario son un resultado estructural de esa rotación agrícola en el campo de disponibilidad de fuerza. En cuanto ámbito localizado, el ayllu ha sido en gran medida, fragmentado e históricamente desestructurado por la acción del proceso de dominación moderno/colonial.

Ayni: Deseo de crear con otros relaciones de correspondencia recíproca que produce un sentimiento común de pertenencia a una sociedad solidaria. Esta relación es el ayni.

Amawt'a: Persona sabia, que sabe pensar y razonar.

Convivialidad: Neologismo que sustituye a la noción occidental de coexistencia de sistemas antagónicos. La convivialidad no apunta a un modus vivendi que permite evitar el enfrentamiento en espera de que las cosas mejoren. La convivialidad pretende ser una relación positiva, para los unos y para los otros, dinamizada por el tinku entre los diferentes sistemas en vigencia, dentro del espacio boliviano 
(la propiedad individual y familiar de los campesinos, la propiedad comunitaria universal de los ayllus y la propiedad privada capitalista). La lógica convivial no sólo tiene relación con la doble fuerza y energía: päch'a, sino también con la interacción (reciprocidad) entre los diversos mundos de la naturaleza, es decir, que trasunta (irradia) lo humano o el mundo de la gente hacia los otros mundos, como el de las deidades, precisamente para cultivar la armonía y el bienestar en el contexto amplio de la comunidad eco-biótica natural.

Jaqi: En lengua aymara significa persona que ha alcanzado una plenitud de atributos humanos. Varón/mujer dentro de la familia y de la comunidad.

Mallkus y Jilaqatas: Autoridades comunales.

Marka: Comunidad originaria de los Andes. Marka es también el nombre que recibe una población o ciudad.

Pacha: $\quad$ Concepto perteneciente al enfoque cosmogónico andino. Pä en aymara es dos; y ch'a es fuerza y energía. En Pächa ambos elementos están operando de manera no separada, sino más bien inter-accionada.

Pachakuti: Pä en aymara es dos, ch'a es fuerza y energía, kutik es retorno. En Pachakuti hay un retorno de una doble fuerza y energía, un retorno de Pächa. En el enfoque cosmogónico andino esto implica un retorno al proceso del Buen Vivir. Un Pachakuti se produce cuando un orden establecido ha perdido su equilibrio y una transformación radical lo cierra para abrir un nuevo ciclo.

Pachamama: Madre naturaleza que provee las energías (materiales y espirituales) para desarrollar y "encaminar" la vida en toda su plenitud.

Qhathu: Viene de qhathusiña que significa reciprocar fuerzas, energías, en una plaza o en un mercado. El qhathu tiene una doble cara. Por un lado, el qhathu como expresión de la 
interacción natural de la vivencia, del modo de ser de la triada producción-feria-celebración. Por otro lado, la feria como mercado. En el qhathu ambas formas están presentes, pese a que muchas veces sólo se lo quiere mirar como mercado regulador de la materialidad de los productos. En el qhathu, la triada producción-feria-celebración interactúa con la yapa y la iraqa. La yapa que es el aumento del producto, y la iraqa es la rebaja del costo de ese producto. En el encuentro de yapa e iraqa, unos, los que están comprando, dirán: bueno que me yape/aumente, y el que está pagando dirá : iraqita/rebájame. Esa interacción entre yapa e iraqa es precisamente el qhathu; de allí viene khathusina, que quiere decir ir conversando, poniéndose de acuerdo sobre algo que se vende-adquiere. En esa relación, además de entrar en contacto personal, se da un encuentro de horizontes culturales, de las dimensiones de la materialidad y espiritualidad. Resulta, entonces, que la compra-venta se hace de todo corazón, pero el corazón conectado al pulmón, con afectividad espiritual, y allí se utiliza la palabra taqi chuyma: que significa comprar-vender de todo corazón/pulmón, no sólo la plata/dinero, sino que el producto te lo llevas de todo corazón, ya sea animal, vegetal o automóvil o lo que fuera. Que tanto el que adquiere como el que vende, se vayan de todo corazón oxigenado, dando su acuerdo de consentimiento y conformidad.

Qullana: La concepción y comprensión de esta palabra expresa:

a) Un espacio territorial donde se produce la mayor cantidad y variedad de hierbas medicinales para usos de la salud material y espiritual.

b) Un espacio territorial que se auto-controla/regula y sanea naturalmente debido a su variedad ecológica altitudinal, con topografías y ecosistemas de producción recíprocamente complementarias.

c) Espacio territorial de mayor carga de energía espiritual, por los contrafuertes de la cordillera de los andes. Espacios donde se consagran el sistema y la jerarquía de los maestros yatiris-chamakanis y los kallawayas, que hacen y cultivan la salud de la materialidad y la espiritualidad en la vida de los pueblos.

d) Un espacio territorial habitado por pueblos dignos que sabiamente pueden interaccionar dimensiones de la materialidad con las de la espiritualidad, de lo privado familiar con 
lo comunitario, haciendo eco a las palabras Tiwa (cuatro en aymara", y Tawa (cuatro en qhichwa). Es decir, de allí emanan las energías a los cuatro ángulos y espacios de la tierra, donde el ayni biótico [ceremonia ritual] es el medio de conversar/templar la armonía de la vida antes que equidades que sólo hacen inequidades.

Los pueblos qullanas tienen estas características, cuyos valores cosmogónicos y conviviales ponen a la balanza de la historia para que pueda correr en la vida. Y de ninguna manera imponen y colonizan.

Qullasuyu: El conjunto de la estructura organizacional propia de los pueblos qullanas.

Suma qamaña: Paradigma de existencia de bienestar y armonía. Qamaña, en aymara, significa vivir, vida. Suma qamaña hace referencia a la buena vida en el sentido integral y estratégico de vida correcta y en armonía con la naturaleza. El Suma Qamaña es un paradigma de vida que toda la humanidad está buscando, porque implica el bienestar y armonía de todos y no de unos pocos. Es una posible solución a la crisis de la civilización moderna.

T'allas: Señores y señoras principales de la comunidad.

Tiwanaku: Civilización ancestral milenaria de la cual se reclaman herederos los aymara-qhichwa. Hoy existen espacios líticos significativos como semilleros civilizatorios ricos en simbología, tecnología y saberes ancestrales.

Yatiri/chamakani: Maestro ritual que sabe conversar haciendo uso de la hoja de coca ritualizada. 


\section{Bibliografía}

ARCHONDO, Rafael et al. 2004. ¿A dónde vamos? Progreso en las diferentes culturas: memoria del foro. La Paz: Agencia Alemana de Cooperación Técnica, Goethe Institut La Paz, Programa de Investigación Estratégica en Bolivia.

BERB, Hans van den. 1987. La tierra no da así nomás. La Paz: Hisbol.

---. $\quad$ y Norbert Schiffers, comps. 1992. La cosmovisión aymara. La Paz: UCBHisbol.

CAPRA, Fritjof. 2000. La trama de la vida. Una nueva perspectiva de los sistemas vivos. Barcelona: Anagrama.

EARKS, John. 1988. Ecología y Agronomía en los andes. La Paz: Hisbol.

GOBIERNO AUTÓNOMO MUNICIPAL DE LA PAZ (GAMLP). 2010. Matrices Civilizatorias; Construcción de políticas Municipales Interculturales. Encuentro y Diálogos de Saberes y Conocimientos. La Paz: GAMLP; Dirección de Gobernabilidad; Delegación Municipal para el Fomento de la Interculturalidad.

GRILLO, Eduardo. ed. 1990. Sociedad y naturaleza en los Andes. Tomo I. Lima: PRATEC/PNUMA.

LOVELOCK, J.E. 1983. Gaia, una nueva visión de la vida sobre la tierra. Madrid: Blume.

MEDINA, Javier. ed. 2001. Suma Qamaña: la comprensión indígena de la buena vida. La Paz: GTZ, Proyecto de Apoyo a la Planificación y Gestión Participativa Municipal: Federación de Asociaciones Municipales de Bolivia.

---. 2000. Diálogo de sordos. Occidente e indianidad. Una aproximación conceptual a la educación intercultural y bilingüe en Bolivia. La Paz: CEBIAE.

---. $\quad$ 1992. Repensar Bolivia. Cicatrices de un viaje hacia sí mismo, 1972-1992. La Paz: HISBOL.

MEMORIA DEL SEMINARIO TALLER VISIONES INDÍGENAS DE DESCENTRALIZACIÓN. 2005. La Paz: Fundación Friederich Ebert Stiftung, Instituto Latinoamericano de Investigaciones Sociales ILDIS, Plural Editores.

TEMPLE, Dominique. 1997. El quid-pro-quo histórico. El malentendido recíproco entre dos civilizaciones antagónicas. Carmen Fernandez y Nancy Arguedas, trads. La Paz: Aruwiyiri.

--- $\quad$ 1986. La dialéctica del don. Ensayo sobre la economía de las comunidades indígenas. La Paz: HISBOL, AUMM y R\&C. 
YAMPARA Huarachi, Simón. 2011. “El Movimiento Katarista de Katari para la Complementariedad MKC frente al TIPNIS".

[www.políticasparabolivia.com/?p=549] página descargada el 15 de noviembre 2011.

---. 2007. “Cosmovisión y economía: El qhatu de la 16 de Julio en El Alto de La Paz". Periódico Pukara 19 (7 de mayo - 7 de junio): 1-2.

[http://www.periodicopukara.com/pasados/pukara-19-articulo-delmes.php] página descargada el 15 de octubre 2011.

---. 2001. El ayllu y la Territorialidad en los Andes. Una aproximación a Chambi Grande. El Alto: CADA/UPEA.

---. $\quad$ 1995. Pachakuti Kandiri en el Paytiti. Reencuentro entre la búsqueda y retorno a la armonía originaria. La Paz: Ed. Qamañ-pacha.

---. $\quad$ 1993. "Economía comunitaria aymara". La cosmovisión aymara. La Paz: UCB-HISBOL. 143-186.

---. 1993. "La sociedad aymara. Sistemas y estructuras sociales de los Andes”. La cosmovisión aymara. La Paz: UCB-HISBOL. 221-240.

---. comp. 1991. Naciones autóctono originarias: vivir-convivir en tolerancia y diferencia. La Paz: Ed. Qamañ-pacha, CADA.

--- 1985. “Adoptar la vía capitalista o la vía comunitaria andina?” Temas en la crisis 24 (enero): 13-16.

---. $\quad$ y Dominique Temple. 2008. Matrices de civilización. Sobre la Teoría Económica de los Pueblos Andinos. El Alto: Qamañ Pacha/GMEA.

(cc) BY-NC-ND

ULS This journal is published by the University Library System of the ULS D-ferle University of Pittsburgh as part of its D-Scribe Digital Publishing Program, and is cosponsored by the University of Pittsburgh Press. 